\title{
Emergência de Plantas Daninhas em Solo Coberto com Palha DE CANA-DE-AÇÚCAR ${ }^{1}$
}

\author{
Weed Emergence in Soil Covered with Sugarcane Harvest Straw Residue \\ CORREIA, N.M. ${ }^{2}$ e DURIGAN, J.C. ${ }^{3}$
}

\begin{abstract}
RESUMO - Com o objetivo de avaliar os efeitos da cobertura do solo, com 0, 5, 10 e 15 tha h $^{-1}$ de palha de cana-de-açúcar da variedade SP 792233 , sobre a emergência de seis espécies de plantas daninhas (Brachiaria decumbens, Digitaria horizontalis, Sida spinosa, Ipomoea grandifolia, Ipomoea hederifolia e Ipomoea quamoclit), foi conduzido um experimento em casa de vegetação do Departamento de Fitossanidade da Universidade Estadual Paulista, campus de Jaboticabal, SP. Cada unidade experimental foi constituída por um vaso plástico com $21,50 \mathrm{~cm}$ de diâmetro e capacidade para quatro litros de solo. Foram semeados $0,112 \mathrm{~g}$ de sementes de $D$. horizontalis, 2,12 g sementes de $I$. quamoclite 50 sementes das demais espécies, por vaso. Foram contabilizadas as plântulas emersas aos 6 e 32 dias após a semeadura (DAS) sob a palha e aos 30, 60 e 90 dias após a remoção da palha (DARP). Constatou-se que a cobertura do solo com 5, 10 e $15 \mathrm{t} \mathrm{ha}^{-1}$ de palha de cana inibiu a emergência de plântulas das espécies $B$. decumbens e $S$. spinosa, sendo o mesmo observado para $D$. horizontalis submetida a 10 e $15 \mathrm{t} \mathrm{ha}^{-1}$ de palha. No entanto, para I. grandifolia e I. hederifolia o número de plantas emersas não diferiu entre as quantidades de palha. Por outro lado, a presença da cobertura morta com palha de cana incrementou a emergência de plântulas de I. quamoclit. Não foram verificados, após a remoção da palha, fluxos expressivos na emergência de plântulas das espécies estudadas.
\end{abstract}

Palavras-chave : Brachiaria decumbens, Digitaria horizontalis, Sida spinosa, Ipomoea spp., cobertura morta.

\begin{abstract}
An experiment was carried out under greenhouse conditions to study the effects of soil coverage with sugarcane harvest straw residue $\left(0,5,10\right.$ and 15 ton ha $\left.\mathrm{a}^{1}\right)$ on the emergence of six weed species (Brachiaria decumbens, Digitaria horizontalis, Sida spinosa, Ipomoea grandifolia, Ipomoea hederifolia and Ipomoea quamoclit) at the Department of Phytosanitation of Universidade Estadual Paulista, Jaboticabal-SP, Brazil. Each experimental unit consisted of one plastic pot (diameter $=21.50 \mathrm{~cm}$; total volume $=4 \mathrm{~L}$ ). $0.112 \mathrm{~g}$ of D. horizontalis seeds, $2.12 \mathrm{~g}$ of $\mathbf{I}$. quamoclit and 50 seeds of the other species seeded per pot. Seedlings under the straw coverage were counted 6 and 32 days after seeding (DAS), and 30, 60 and 90 days after straw removal (DASR). Soil coverage with 5, 10 and $15 t h^{1}$ of sugarcane harvest straw residue inhibited the emergence of $\mathrm{B}$. decumbens and $\mathrm{S}$. spinosa seedlings. The same was observed for $\boldsymbol{D}$. horizontalis submitted to coverage with 10 and $15 t h a^{1}$ of sugarcane harvest straw residue. On the other hand, the number of I. grandifolia and I. hederifolia seedlings did not differ among the amounts of straw. Emergence of I. quamoclit seedlings increased with the presence of sugarcane harvest straw residue coverage. $N$ expressive weed fluxes were observed after straw residue removal.
\end{abstract}

Key words: Brachiaria decumbens, Digitaria horizontalis, Sida spinosa, Ipomoea spp., mulching.

Recebido para publicação em 29.5.2003 e na forma revisada em 5.3.2004.

Eng.-Agr-.., M.S., Aluna do Programa de Pós-Graduação em Agronomia (Produção Vegetal) do curso de Doutorado, Universidade Estadual Paulista - UNESP, Câmpus de Jaboticabal-SP, <nubiacorreia@hotmail.com>; ${ }^{3}$ Eng.-Agro., Dr., Professor. do Departamento de Fitossanidade da UNESP, Câmpus de Jaboticabal, Via de Acesso Prof. Paulo Donato Castellane, s/n., 14884-900 Jaboticabal-SP, $<$ jcdurigan@fcav.unesp.br>. 


\section{INTRODUÇÃO}

Na cultura da cana-de-açúcar, a colheita sem queimada deixa, sobre o solo, uma espessa camada de palha, que pode superar $20 \mathrm{t} \mathrm{ha}^{-1}$. A palha, associada às modificações técnicas necessárias para implementar a colheita mecânica da cultura, criou um novo sistema de produção de cana-de-açúcar, popularmente denominado cana crua (Velini \& Negrisoli, 2000).

A germinação é um processo-chave na organização e dinâmica das espécies vegetais, sendo muito sensível à cobertura do solo. Resíduos culturais na superfície do solo alteram a umidade, luminosidade e temperatura do solo, principais variáveis no controle da dormência e germinação de sementes. A cobertura, também, pode prejudicar as plântulas em desenvolvimento, devido à barreira física, causando o estiolamento destas e tornando-as suscetiveis aos danos mecânicos. Pode proporcionar, ainda, ações químicas decorrentes de mudanças na relação $\mathrm{C} / \mathrm{N}$ ou por alelopatia, além de favorecer o desenvolvimento de insetos e microrganismos, que alimentam ou hospedam as sementes e a parte aérea das plantas daninhas (Correia \& Rezende, 2002).

Dessa forma, a palha de cana mantida na superfície do solo pode interferir na dormência, germinação e mortalidade das sementes de plantas daninhas, provocando modificações da comunidade infestante. Essas mudanças, no entanto, são muito específicas e dinâmicas, pois dependem da quantidade de palha e, principalmente, da espécie daninha, que pode ser favorecida ou não pela cobertura morta.

O objetivo do presente trabalho foi avaliar os efeitos da cobertura do solo com palha de cana-de-açúcar sobre a emergência de Brachiaria decumbens, Digitaria horizontalis, Sida spinosa, Ipomoea grandifolia, Ipomoea hederifolia e Ipomoea quamoclit, que são espécies infestantes desta cultura.

\section{MATERIAL E MÉTODOS}

O experimento foi conduzido no período de 5 de maio a 7 de setembro de 2002, em casa de vegetação do Departamento de Fitossanidade da Universidade Estadual Paulista, campus de Jaboticabal, SP.
Foi utilizado um Latossolo VermelhoEscuro distroférrico, representativo dos canaviais da região de Jaboticabal, coletado na camada do subsolo e peneirado em malha de $5 \mathrm{~mm}$. A camada de subsolo foi escolhida por apresentar reduzida quantidade de propágulos de plantas daninhas, comparada à camada superficial do solo. As características químicas do solo utilizado no experimento foram: $\mathrm{pH}\left(\mathrm{CaCl}_{2}\right)=4,8$; M.O. $\left(\mathrm{g} \mathrm{dm}^{-3}\right)=10 ; \mathrm{P}\left(\mathrm{mg} \mathrm{dm}^{-3}\right)$ $=6 ; \mathrm{H}+\mathrm{Al}, \mathrm{K}, \mathrm{Ca}, \mathrm{Mg}, \mathrm{SB}$ e $\mathrm{T}\left(\mathrm{mmol}_{\mathrm{c}} \mathrm{dm}^{-3}\right)=$ $22 ; 0,6 ; 10 ; 4 ; 14,6 ; 36,6$, respectivamente; e $\mathrm{V}(\%)=40$. Esse solo recebeu $80 \mathrm{mg} \mathrm{L}^{-1}$ de $\mathrm{N}$; $88 \mathrm{mg} \mathrm{L}^{-1}$ de P; $88 \mathrm{mg} \mathrm{L}^{-1}$ de K; $24 \mathrm{mg} \mathrm{L}^{-1}$ de S; $1 \mathrm{mg} \mathrm{L}^{-1} \mathrm{de} \mathrm{Cu}$; e $3 \mathrm{mg} \mathrm{L}^{-1}$ de $\mathrm{Zn}$. Quatro meses antes da semeadura aplicou-se no solo $1 \mathrm{~g} \mathrm{~L}^{-1}$ de calcário.

Cada unidade experimental foi constituída por um vaso plástico com $21,50 \mathrm{~cm}$ de diâmetro e capacidade para quatro litros de solo.

O delineamento experimental utilizado foi o de blocos ao acaso, com quatro repetições, no esquema fatorial $4 \times 6$, avaliando-se os efeitos da cobertura do solo com $0,5,10$ e $15 \mathrm{t} \mathrm{ha}^{-1}$ de palha de cana da variedade SP 792233 sobre a emergência de seis espécies de plantas daninhas (Brachiaria decumbens, Digitaria horizontalis, Sida spinosa, Ipomoea grandifolia, Ipomoea hederifolia e Ipomoea quamoclit).

Após a colheita mecânica de plantas de cana, coletou-se a palha remanescente no solo, a qual foi encaminhada à casa de vegetação, onde se procedeu ao término da sua secagem.

Foram semeados 0,112 g de sementes de D. horizontalis, $2,12 \mathrm{~g}$ sementes de I. quamoclit e 50 sementes das demais espécies, por vaso. As sementes foram distribuídas homogeneamente no vaso e incorporadas até $1 \mathrm{~cm}$ de profundidade na superfície do solo. Após a semeadura, cada parcela recebeu a palha de cana, depositada em camada uniforme e em quantidade equivalente à preestabelecida para cada tratamento. A palha foi cortada em fragmentos menores, com tamanho inferior ou igual ao diâmetro do vaso.

A irrigação foi realizada com o propósito de manter a capacidade de campo do solo próxima a $75 \%$.

O experimento foi dividido em duas etapas distintas. Na primeira avaliaram-se as 
plântulas emersas em solo sob cobertura de palha de cana e, na segunda, a emergência destas após a remoção da palha.

O número de plântulas emersas em solo sob palha de cana foi obtido aos 6 e 32 dias após a semeadura (DAS); aos 32 DAS a emergência das plântulas já havia estabilizado. Foram consideradas emersas as plântulas visiviveis em cada avaliação, com mais de $0,5 \mathrm{~cm}$ de parte aérea acima da camada de palha. A segunda avaliação foi acumulativa em relação às plântulas contabilizadas aos 6 DAS. Aos 32 DAS as plantas foram cortadas rente ao solo, acondicionadas em sacos de papel e levadas à estufa com circulação forçada de ar a $62{ }^{\circ} \mathrm{C}$, até atingirem peso constante, sendo, em seguida, pesadas, para obtenção da matéria seca da parte aérea.

Após a coleta das plantas, retirou-se a palha dos vasos e, aos 30, 60 e 90 dias após essa remoção, avaliou-se o número de plântulas emersas de forma acumulativa, considerando-se, também, as plântulas visíveis em cada avaliação, com mais de $0,5 \mathrm{~cm}$ de parte aérea acima do solo.

Os dados obtidos foram submetidos ao teste $\mathrm{F}$ na análise de variância e, quando significativos $(p<0,01$ ou $p<0,05)$, as médias foram comparadas com o auxílio do teste de Tukey a $5 \%$ de probabilidade.

\section{RESULTADOS E DISCUSSÃO}

Houve efeito significativo $(\mathrm{p}<0,01)$ das espécies de plantas daninhas e da palha de cana na emergência de plântulas, nas duas épocas de avaliação, e na matéria seca destas. Aos 30, 60 e 90 dias após a remoção da palha (DARP), as espécies de plantas daninhas diferiram $(p<0,01)$ quanto à emergência de plântulas, porém a palha de cana não influenciou essa emergência.

A interação espécie de planta daninha $\mathrm{x}$ palha de cana foi significativa para emergência de plântulas, aos 6 e 32 dias após a semeadura (DAS), e acúmulo de matéria seca $(p<0,01)$, indicando uma dependência entre os fatores, ou seja, as espécies de plantas daninhas não tiveram o mesmo efeito dentro de cada quantidade de palha, ou as quantidades de palhas não apresentaram o mesmo comportamento em relação a cada espécie de planta daninha. Neste estudo, optou-se pela análise do desdobramento da quantidade de palha de cana dentro de cada espécie de planta daninha.

Por outro lado, a interação espécie de planta daninha $\mathrm{x}$ palha de cana não foi significativa para emergência de plântulas contabilizadas aos 30, 60 e 90 DARP; mesmo assim, realizouse o desdobramento da interação, a fim de se observar a emergência de cada espécie de planta daninha após a remoção da palha de cana do solo.

Para Brachiaria decumbens, aos $6 \mathrm{e}$ 32 DAS, a cobertura do solo com palha de cana crua inibiu a emergência de plântulas, porém não houve diferença significativa entre as quantidades de 5,10 e $15 \mathrm{t} \mathrm{ha}^{-1}$. A matéria seca dessas plântulas, sob 10 e $15 \mathrm{t} \mathrm{ha}^{-1} \mathrm{de}$ palha, foi significativamente reduzida em média de $64 \%$, comparado ao tratamento sem palha (Tabela 1). Após a remoção da palha, nas três épocas de avaliação, não houve diferença significativa entre os tratamentos no número de plântulas emersas (Tabela 4). A cobertura do solo com palha de cana crua promoveu a perda da viabilidade de sementes de $B$. decumbens, pois aquelas que não emergiram na presença da palha não o fizeram após a sua remoção, devido a efeitos físicos, químicos e/ ou biológicos da cobertura. Pode-se inferir, então, que a palha de cana mantida sobre o solo interfere na emergência de plântulas de $B$. decumbens e, conseqüentemente, no seu banco de sementes no solo.

O efeito físico da cobertura morta é muito importante na regulação da germinação e na taxa de sobrevivência das plântulas de algumas espécies de plantas daninhas. Os efeitos sobre o processo germinativo podem ser exemplificados com a redução da germinação de sementes fotoblásticas positivas, das sementes que requerem determinado comprimento de onda e das sementes que necessitam de grande amplitude de variação térmica para inibir o processo germinativo. O efeito físico da palha também reduz as chances de sobrevivência das plântulas das plantas daninhas com pequena quantidade de reservas nos diásporos (Pitelli \& Durigan, 2001).

A cobertura do solo com 10 e $15 \mathrm{t} \mathrm{ha}^{-1}$ de palha proporcionou redução na emergência de

Planta Daninha, Viçosa-MG, v.22, n.1, p.11-17, 2004 
plântulas de Digitaria horizontalis e no seu acúmulo de matéria seca (Tabela 1). Não houve diferença significativa entre as coberturas de 0 e 5 t ha ${ }^{-1}$. Verificou-se, também, que até os 60 dias após a remoção da palha (DARP) não houve diferença significativa entre os tratamentos no número de plântulas emersas; contudo, aos 90 DARP, observou-se maior número de plantas nos vasos anteriormente com 5, 10 e 15 t ha $^{-1}$ de palha. Mesmo assim, o número médio de plantas constatadas por vaso é considerado baixo, uma vez que o número total de plântulas emersas nos vasos sem palha foi 58 e $76 \%$ superior ao das coberturas de 10 e $15 \mathrm{t} \mathrm{ha}^{-1}$, respectivamente (Tabela 4).

Lorenzi (1993) mencionou que a manutenção de aproximadamente $12 \mathrm{t} \mathrm{ha}^{-1} \mathrm{de}$ cobertura morta de cana na superfície do solo proporcionou o melhor controle das plantas daninhas (100\%), e, com a sua remoção total, não houve controle $(0 \%)$. O nivel de controle das plantas daninhas aumentou proporcionalmente à quantidade de palha deixada na superficie do solo. As principais espécies de plantas daninhas constatadas no experimento foram: Portulaca oleracea, Amaranthus deflexus, Panicum maximum, Eleusine indica e Digitaria horizontalis.

Em outro trabalho, Medeiros \& Christoffoleti (2001) constataram que as espécies Brachiaria decumbens, Brachiaria plantaginea, Digitaria horizontalis e Panicum maximum apresentaram um desenvolvimento reduzido nos tratamentos em que houve a presença de palha de cana, contrariamente ao das parcelas sem palha. Os autores relataram também que, embora as espécies Euphorbia heterophylla e Ipomoea hederifolia tenham emergido nas parcelas sem palha, verificou-se que nas áreas com palha houve maior taxa de emergência dessas espécies.

Para Sida spinosa, a cobertura do solo, seja com 5,10 ou $15 \mathrm{t} \mathrm{ha}^{-1}$, inibiu acentuadamente a emergência e a matéria seca das plântulas dessa espécie (Tabela 2). No entanto, nas três avaliações, após a remoção da palha, o número de plântulas emersas não diferiu entre os

Tabela 1 - Número de plantas por vaso de Brachiaria decumbens e Digitaria horizontalis aos 6 e 32 dias após a semeadura (DAS) e matéria seca das plantas por vaso aos 32 DAS, submetidas a quatro quantidades de palha de cana crua sobre o solo. UNESP, Jaboticabal-SP, 2002

\begin{tabular}{|c|c|c|c|c|c|c|}
\hline \multirow{2}{*}{$\begin{array}{l}\text { Palha } \\
\left(\mathrm{t} \mathrm{ha}^{-1}\right)\end{array}$} & \multicolumn{3}{|c|}{ Brachiaria decumbens } & \multicolumn{3}{|c|}{ Digitaria horizontalis } \\
\hline & $6 \mathrm{DAS}$ & $32 \mathrm{DAS}$ & Matéria seca $(\mathrm{g})$ & 6 DAS & 32 DAS & Matéria seca $(\mathrm{g})$ \\
\hline 0 & $15,75 \mathrm{a}^{1 /}$ & $17,75 \mathrm{a}$ & $3,80 \mathrm{a}$ & $47,75 \mathrm{a}$ & $57,50 \mathrm{a}$ & $6,12 \mathrm{a}$ \\
\hline 5 & $6,25 \mathrm{~b}$ & $9,75 \mathrm{~b}$ & $2,93 \mathrm{a}$ & $36,00 \mathrm{a}$ & $51,00 \mathrm{a}$ & $4,88 \mathrm{a}$ \\
\hline 10 & $4,75 \mathrm{~b}$ & $8,50 \mathrm{~b}$ & $1,54 \mathrm{~b}$ & $11,00 \mathrm{~b}$ & $20,50 \mathrm{~b}$ & $1,75 \mathrm{~b}$ \\
\hline 15 & $3,50 \mathrm{~b}$ & $7,00 \mathrm{~b}$ & $1,18 \mathrm{~b}$ & $3,75 \mathrm{~b}$ & $9,50 \mathrm{~b}$ & $0,65 \mathrm{~b}$ \\
\hline
\end{tabular}

${ }^{1 /}$ Médias seguidas pela mesma letra não diferem significativamente entre si pelo teste de Tukey a 5\% de probabilidade.

Tabela 2 - Número de plantas por vaso de Sida spinosa e Ipomoea grandifolia aos 6 e 32 dias após a semeadura (DAS) e matéria seca das plantas por vaso aos 32 DAS, submetidas a quatro quantidades de palha de cana crua sobre o solo. UNESP, Jaboticabal-SP, 2002

\begin{tabular}{|c|c|c|c|c|c|c|}
\hline $\begin{array}{l}\text { Palha } \\
\left(\mathrm{t} \mathrm{ha}^{-1}\right)\end{array}$ & \multicolumn{3}{|c|}{ Sida spinosa } & \multicolumn{3}{|c|}{ Ipomoea grandifolia } \\
\hline 0 & $6,00 \mathrm{a}^{1 /}$ & $7,25 \mathrm{a}$ & 0,23 a & $15,75 \mathrm{a}$ & $16,25 \mathrm{a}$ & $2,93 \mathrm{a}$ \\
\hline 5 & $0,25 \mathrm{~b}$ & $0,25 \mathrm{~b}$ & $0,007 \mathrm{~b}$ & $6,50 \mathrm{~b}$ & $11,75 \mathrm{a}$ & $1,24 \mathrm{~b}$ \\
\hline 10 & $0,00 \mathrm{~b}$ & $0,50 \mathrm{~b}$ & $0,015 \mathrm{~b}$ & $5,50 \mathrm{~b}$ & $16,25 \mathrm{a}$ & $1,81 \mathrm{ab}$ \\
\hline
\end{tabular}

${ }^{1 /}$ Médias seguidas pela mesma letra não diferem significativamente entre si pelo teste de Tukey a 5\% de probabilidade. 
tratamentos (Tabela 4), confirmando mais uma vez o efeito da palha de cana crua não apenas na germinação e emergência de plântulas, mas também na perda da viabilidade de sementes de plantas daninhas.

No estudo realizado por Martins et al. (1999), a cobertura do solo com palha de cana reduziu significativamente a emergência das plântulas de Sida rhombifolia, sendo esse efeito mais intenso quanto maior a quantidade de palha utilizada. Entretanto, a remoção da cobertura promoveu a emergência das plântulas dessa espécie, principalmente nos tratamentos de 4 a $10 \mathrm{t} \mathrm{ha}^{-1}$, devido à superação da dormência causada ou mantida pela cobertura morta.

Gomide (1993) constatou menor infestação, com valores mínimos ou nulos, das espécies Indigofera hirsuta, Sida rhombifolia e Sida spp. nas parcelas cujos tratamentos tinham palha de cana; contudo, onde se fez o multicultivo, a população destas infestantes foi maior. A porcentagem de controle exercida pela palha do cultivar SP 701143 sobre a germinação de propágulos de Cyperus spp. foi mais eficaz, apresentando um índice de controle de 98,7 a 100\%; a palha do cultivar SP 711406 proporcionou uma porcentagem de controle de 75 a $100 \%$ nos tratamentos com palha.

A presença da cobertura morta cria condições para instalação de uma densa e diversificada microbiocenose na camada superficial do solo. Na composição específica desta microbiocenose há uma grande quantidade de organismos que podem utilizar sementes e plântulas de plantas daninhas como fontes de energia e matéria (Pitelli \& Durigan, 2001). Ressalta-se, também, que o processo de decomposição da palha na superfície do solo libera gradativamente uma série de compostos orgânicos denominados aleloquímicos, que também podem interferir diretamente na germinação e emergência das plantas daninhas, assim como na perda da viabilidade das suas sementes. Segundo Almeida (1991), os resíduos vegetais de decomposição rápida têm, geralmente, ação alelopática intensa, mas de curta duração, enquanto os de decomposição lenta têm ação por mais tempo. A atividade alelopática depende diretamente da qualidade e quantidade do material vegetal depositado na superfície, do tipo de solo, da população microbiana, das condições climáticas e da composição específica da comunidade de plantas daninhas.

Quintela et al. (2002), estudando o efeito físico e/ou alelopático da palha de cana sobre a emergência de três espécies de plantas daninhas, observaram que, para a espécie Cynodon dactylon, o tratamento água + palha proporcionou redução significativa na emergência de plântulas; a aplicação do extrato aquoso da palha da variedade RB 835089 inibiu completamente a emergência de plântulas, sugerindo forte efeito alelopático. No entanto, as espécies Cyperus rotundus e Brachiaria decumbens não foram completamente inibidas; na aplicação do extrato, a emergência de plântulas foi maior do que a obtida com água + palha. O efeito físico da palha foi mais pronunciado do que o provável efeito alelopático do extrato aquoso, para estas duas espécies de plantas daninhas.

Observa-se na Tabela 2 o efeito dos tratamentos sobre a emergência e matéria seca de plântulas de Ipomoea grandifolia. Constatouse que inicialmente, aos 6 DAS, a cobertura morta de cana reduziu a emergência das plântulas; todavia, com o decorrer do tempo, as plântulas desses tratamentos emergiram normalmente, alcançando aos 32 DAS valores estatisticamente similares ao do tratamento sem palha. Quanto ao acúmulo de matéria seca, verificou-se que as plantas crescidas nos vasos com $5 \mathrm{t} \mathrm{ha}^{-1}$ de palha apresentaram menor massa, diferindo significativamente do tratamento sem palha. Nas três avaliações realizadas, o número de plântulas emersas de I. grandifolia após a remoção da palha foi maior nos vasos anteriormente com $5 \mathrm{t} \mathrm{ha}^{-1}$ de palha; contudo, o número total de $I$. grandifolia deste tratamento, antes e após a remoção da palha, foi inferior aos dos demais tratamentos (Tabela 5).

De acordo com Martins et al. (1999), a presença da cobertura implementou a emergência das plântulas de I. grandifolia apenas nas quantidades de 2 a $8 \mathrm{t} \mathrm{ha}^{-1}$ de palha de cana crua. A retirada da cobertura não promoveu, em comparação à testemunha, a emergência das plântulas dos tratamentos, nivelando os resultados do total de plântulas emersas. 
Para Ipomoea hederifolia (Tabela 3), observou-se o mesmo efeito temporal da palha de cana na emergência de plântulas. Aos 6 DAS, a palha de cana inibiu a emergência de plântulas de $I$. hederifolia, comparado à testemunha, porém, aos 32 DAS, não houve diferença significativa entre os tratamentos. Por outro lado, as plantas crescidas nos vasos sem palha apresentaram maior matéria seca, diferindo significativamente das demais coberturas. O mesmo foi observado por Azania et al. (2002), utilizando quantidades similares de palha de cana.

Constatou-se, também, nas três avaliações realizadas, após a remoção da palha de cana crua, que o número de plântulas emersas não diferiu entre os tratamentos, com valor médio inferior a 0,20 planta por vaso (Tabela 5).

A palha de cana crua mantida na superficie do solo reduziu a emergência de plântulas de Ipomoea quamoclit aos 6 DAS; todavia, aos 32 DAS, observou-se efeito contrário, ou seja, em comparação ao tratamento sem palha, a presença da cobertura morta de cana implementou o número de plântulas emersas nas três quantidades estudadas. Quanto à matéria seca, as quantidades de 10 e $15 \mathrm{tha}^{-1}$ de palha proporcionaram maior acúmulo de massa dessa espécie, não diferindo significativamente do tratamento sem palha (Tabela 3). No entanto, Azania et al. (2002) afirmaram que $15 \mathrm{t} \mathrm{ha}^{-1}$ de palha de cana inibiram a emergência de plântulas de I. quamoclit, porém, com 5 e 10 t ha $^{-1}$ de palha, o número de plantas emersas não diferiu do tratamento sem palha.

Após a remoção da palha, não se constatou diferença entre as coberturas nas três épocas de avaliação (Tabela 5).

Percebe-se, então, que no sistema de colheita da cana crua, com a manutenção da palha de cana na superfície do solo, deverá haver uma redução na densidade populacional de $B$. decumbens, $S$. spinosa e $D$. horizontalis para esta, em quantidades de palha iguais ou superiores a $10 \mathrm{t} \mathrm{ha}^{-1}$. No entanto, as espécies

Tabela 3 - Número de plantas por vaso de Ipomoea hederifolia e Ipomoea quamoclit aos 6 e 32 dias após a semeadura (DAS) e matéria seca das plantas por vaso aos 32 DAS, submetidas a quatro quantidades de palha de cana crua sobre o solo. UNESP, Jaboticabal-SP, 2002

\begin{tabular}{|c|c|c|c|c|c|c|}
\hline \multirow{2}{*}{$\begin{array}{l}\text { Palha } \\
\left(\mathrm{t} \mathrm{ha}^{-1}\right)\end{array}$} & \multicolumn{3}{|c|}{ Ipomoea hederifolia } & \multicolumn{3}{|c|}{ Ipomoea quamoclit } \\
\hline & 6 DAS & 32 DAS & Matéria seca $(\mathrm{g})$ & 6 DAS & $32 \mathrm{DAS}$ & Matéria seca $(\mathrm{g})$ \\
\hline 0 & $12,50 \mathrm{a}^{1 /}$ & $13,50 \mathrm{a}$ & $2,69 \mathrm{a}$ & $11,50 \mathrm{a}$ & $33,75 \mathrm{~b}$ & $3,06 \mathrm{ab}$ \\
\hline 5 & $3,50 \mathrm{~b}$ & $8,25 \mathrm{a}$ & $1,05 \mathrm{~b}$ & $0,00 \mathrm{~b}$ & $40,50 \mathrm{ab}$ & $1,92 \mathrm{~b}$ \\
\hline 10 & $4,50 \mathrm{~b}$ & $8,75 \mathrm{a}$ & $1,55 \mathrm{~b}$ & $2,50 \mathrm{~b}$ & $45,25 \mathrm{a}$ & $3,19 \mathrm{a}$ \\
\hline 15 & $5,25 \mathrm{~b}$ & $8,50 \mathrm{a}$ & $1,41 \mathrm{~b}$ & $2,75 \mathrm{~b}$ & $34,50 \mathrm{ab}$ & $3,75 \mathrm{a}$ \\
\hline
\end{tabular}

${ }^{1 /}$ Médias seguidas pela mesma letra não diferem significativamente entre si pelo teste de Tukey a 5\% de probabilidade.

Tabela 4 - Número de plantas por vaso de Brachiaria decumbens, Digitaria horizontalis e Sida spinosa aos 30,60 e 90 dias após a remoção da palha (DARP) da superfície do solo. UNESP, Jaboticabal-SP, 2002

\begin{tabular}{|c|c|c|c|c|c|c|c|c|c|}
\hline \multirow{2}{*}{$\begin{array}{l}\text { Palha } \\
\left(\mathrm{t} \mathrm{ha}^{-1}\right)\end{array}$} & \multicolumn{3}{|c|}{ Brachiaria decumbens } & \multicolumn{3}{|c|}{ Digitaria horizontalis } & \multicolumn{3}{|c|}{ Sida spinosa } \\
\hline & \multicolumn{9}{|c|}{ DARP } \\
\hline 0 & 1,00 & 1,25 & 1,25 & 1,50 & 1,50 & $1,50 \mathrm{~b}^{1 /}$ & 0,25 & 0,50 & 0,50 \\
\hline 5 & 1,25 & 1,25 & 1,25 & 2,75 & 3,50 & $4,50 \mathrm{a}$ & 0,00 & 0,00 & 0,00 \\
\hline 15 & 1,25 & 1,25 & 1,50 & 2,25 & 3,75 & $4,50 \mathrm{a}$ & 0,00 & 0,00 & 0,25 \\
\hline
\end{tabular}

${ }^{1 /}$ Médias seguidas pela mesma letra não diferem significativamente entre si pelo teste de Tukey a 5\% de probabilidade. 
Tabela 5 - Número de plantas por vaso de Ipomoea grandifolia, Ipomoea hederifolia e Ipomoea quamoclit aos 30, 60 e 90 dias após a remoção da palha (DARP) da superfície do solo. UNESP, Jaboticabal-SP, 2002

\begin{tabular}{|c|c|c|c|c|c|c|c|c|c|}
\hline \multirow{3}{*}{$\begin{array}{l}\text { Palha } \\
\left(\mathrm{t} \mathrm{ha}^{-1}\right)\end{array}$} & \multicolumn{3}{|c|}{ Ipomoea grandifolia } & \multicolumn{3}{|c|}{ Ipomoea hederifolia } & \multicolumn{3}{|c|}{ Ipomoea quamoclit } \\
\hline & 30 & 60 & 90 & 30 & 60 & 90 & 30 & 60 & 90 \\
\hline & \multicolumn{9}{|c|}{ DARP } \\
\hline 0 & $0,50 \mathrm{~b}^{1 /}$ & $1,00 \mathrm{ab}$ & $1,25 \mathrm{ab}$ & 0,00 & 0,00 & 0,25 & 2,00 & 2,25 & 2,25 \\
\hline 5 & $3,00 \mathrm{a}$ & $3,00 \mathrm{a}$ & $3,75 \mathrm{a}$ & 0,25 & 0,50 & 0,50 & 0,75 & 1,75 & 1,75 \\
\hline 10 & $0,25 \mathrm{~b}$ & $0,25 \mathrm{~b}$ & $1,00 \mathrm{~b}$ & 0,00 & 0,00 & 0,00 & 0,50 & 1,00 & 1,25 \\
\hline 15 & $0,50 \mathrm{~b}$ & $0,75 \mathrm{ab}$ & $1,50 \mathrm{ab}$ & 0,00 & 0,00 & 0,00 & 1,50 & 1,50 & 1,50 \\
\hline
\end{tabular}

${ }^{1}$ Médias seguidas pela mesma letra não diferem significativamente entre si pelo teste de Tukey a $5 \%$ de probabilidade.

I. grandifolia e I. hederifolia tendem a manter-se como plantas-problema, enquanto I. quamoclit deverá aumentar a sua densidade populacional.

\section{LITERATURA CITADA}

ALMEIDA, F. S. Controle de plantas daninhas em plantio direto. Londrina: IAPAR, 1991. 34 p. (IAPAR. Circular 67)

AZANIA, A. A. P. M. et al. Interferência da palha de canade-açúcar (Saccharum spp.) na emergência de espécies de plantas daninhas da família convolvulaceae. Planta

Daninha, v. 20, n. 2, p. 207-212, 2002.

CORREIA, N. M.; REZENDE, P. M. Manejo integrado de plantas daninhas na cultura da soja. Lavras: Editora UFLA, 2002. 55 p. (Boletim Agropecuário, 51)

GOMIDE, M. B. Potencialidades alelopáticas dos restos culturais de dois cultivares de cana-de-açúcar (Saccharum sp.), no controle de algumas plantas daninhas. 1993. $99 \mathrm{f}$. Tese (Doutorado em Fitotecnia) Escola Superior de Agricultura "Luiz de Queiroz", Piracicaba, 1993.

LORENZI, H. Efeito da palha da cana no controle das plantas daninhas. In: CONGRESSO BRASILEIRO DE HERBICIDAS E PLANTAS DANINHAS, 19., 1993, Londrina. Resumos... Londrina: Sociedade Brasileira da Ciência das Plantas Daninhas, 1993. p. 28-29.
MARTINS, D. et al. Emergência em campo de dicotiledôneas infestantes em solo coberto com palha de cana-de-açúcar. Planta Daninha, v. 17, n. 1, p. 151-161, 1999.

MEDEIROS, D.; CHRISTOFFOLETI, P. J. Efeito da palha de cana-de-açúcar em áreas de colheita mecanizada sem queima sobre a infestação de plantas daninhas e eficácia de herbicidas. In: PRADO, R.; JORRÍN, J. V. Uso de herbicidas en la agricultura del siglo XXI. Córdoba: Universidad de Córdoba, 2001. p. 599-605.

PITELLI, R. A.; DURIGAN, J. C. Ecologia das plantas daninhas no sistema plantio direto. In: ROSSELLO, R. D. Siembra directa en el cono sur. Montevideo: PROCISUR, 2001. p. 203-210.

QUINTELA, A. C. R. et al. Controle físico e/ou alelopático de três plantas daninhas pelo palhiço de duas variedades de cana-de-açúcar, em condições de casa-de-vegetação. In: CONGRESSO NACIONAL DA SOCIEDADE DOS TÉCNICOS AÇUCAREIROS E ALCOOLEIROS DO BRASIL, 8., 2002, Recife. Anais... Recife: STAB, 2002. p. 190-194.

VELINI, E. D.; NEGRISOLI, E. Controle de plantas daninhas em cana crua. In: CONGRESSO BRASILEIRO DA CIÊNCIA DAS PLANTAS DANINHAS, 22., 2000, Foz do Iguaçu. Anais... Foz do Iguaçu: Sociedade Brasileira da Ciência das Plantas Daninhas, 2000. p. 148-164. 